\title{
Breve discussão sobre o traço unário e o objeto a na constituição subjetiva
}

Brief discussion on unary trait and the object a to the subjective constitution

Breve discusión sobre rasgo unario y el objeto a de la constitución subjetiva

\author{
Brenda Rodrigues da Costa Neves* \\ Angela Maria Resende Vorcaro*
}

\begin{abstract}
Resumo
Os efeitos da submissão da criança à linguagem pela via de um agente do Outro permite configurar a formação do inconsciente e o desenvolvimento do ego, promovendo a constituição subjetiva. Uma marca antecipatória no organismo é assim inscrita, marcando-o com a linguagem. Considerando as suposições da clínica com bebês calcadas nessa perspectiva, pretendemos, neste artigo, ressaltar a participação ativa do infans nessa instalação do simbólico. Trata-se do movimento pulsional que interceptará os atos de fala do agente Outro para neles se alojar. Propomos, assim, uma breve discussão da articulação do objeto $a$ ao traço unário na constituição subjetiva, situando a especificidade da pulsão. Ressaltamos, ainda, a importância da intervenção a tempo proposta pela psicanálise na clínica com crianças pequenas.

Palavras-chave: sujeito; traço unário; constituição subjetiva; objeto $a$.
\end{abstract}

\begin{abstract}
The effects of children's submission to language through the Other allows an individual to set the formation of the unconscious and ego development, promoting the subjective constitution. An anticipatory sign in the body is thus placed, marking it with the language. Considering the assumptions of clinical work with babies based on this perspective, this article aims to highlight the active participation of the infans in this establishment of the symbolic. It is the instinctive movement that will intercept the speech acts of the Other in order to be stored in them. Thus, we propose a brief discussion on the articulation of the object a with the unary trait in the subjective constitution, locating the specificity of the drive. We emphasize the
\end{abstract}

\footnotetext{
Mestra em Estudos Psicanalíticos pela UFMG, integrante do grupo de pesquisa coordenado pela Prof. ${ }^{a}$ Dr. ${ }^{a}$ Ângela Vorcaro sobre "O método na clínica com bebês", psicóloga pela Proteção Social Especial na Prefeitura Municipal de Sete Barras-SP.

** Professora doutora adjunta do Departamento de Psicologia da UFMG; membro do Centro Outrarte (IEL/Campinas) e do Grupo Anpepp: Psicanálise, Infância, Educação; psicanalista.
} 
importance of timely intervention proposed by psychoanalysis in the clinic with young children.

Keywords: subject; unary trait; subjective constitution; object $a$.

\section{Resumen}

Los efectos de someter los niños al lenguaje por la vía de un agente Otro permite configurar la formación del inconsciente y el desarrollo del ego, promoviendo la constitución subjetiva. Una marca anticipatoria en el organismo es inscrita de esta forma, marcándola con el lenguaje. Considerando las suposiciones de la clínica con bebes fundamentadas en esta perspectiva, pretendemos, en este artículo, resaltar la participación activa do infans en esa instalación de lo simbólico. Se trata de un movimiento pulsional que interceptará los hechos de habla del agente Otro para alojarse en ellos. Proponemos, así, una breve discusión de la articulación del objeto $a$ al trazo unario en la constitución subjetiva, situando lo especifico de la pulsión. Resaltamos, todavía, la importancia de la intervención a tiempo propuesta por el psicoanálisis en la clínica con niños pequeños

Palabras clave: sujeto; rasgo unário; la constitución subjetiva; objeto $a$.

\section{A} relação entre os efeitos da submissão da criança à linguagem pela via da presença do agente do Outro permite configurar a formação do inconsciente e o desenvolvimento do ego conforme promove um passo imprescindível para a constituição subjetiva: para se tornar um sujeito desejante, o infans não prescinde, antes, dessa suposição de desejo. Tal movimento pode inscrever uma marca antecipatória no organismo, localizando-o num lugar distinto, ao mesmo tempo em que demarca essa passagem por ali. São nos atos de fala dirigida ao organismo neonato que essa antecipação subjetiva confirma a existência de um bebê, ou seja, ao reconhecer e articular as manifestaçôes corporais da criança, o agente materno franqueia a transposição de suas manifestações para a ordem da linguagem, e a criança, ao se alienar aos sentidos dados pelos semelhantes, termina por antecipar sua identidade antes mesmo de se verificar isso. Considerando as suposições da clínica com bebês calcados nessa perspectiva, pretendemos, neste artigo, ressaltar que, se esse movimento de reconhecimento faz a passagem da esfera da natureza para o campo da cultura, distinguindo um sujeito agora marcado pela linguagem, outros elementos se desenrolam daí, exigindo a participação 
ativa do infans nessa instalação do simbólico. Trata-se do movimento pulsional que interceptará os atos de fala do agente Outro, para neles se alojar. É nessa perspectiva que propomos fazer uma breve discussão da articulação do objeto $a$ ao traço unário no processo de constituição subjetiva.

Caso alguém se encarne como destinatário do endereçamento de um apelo da criança pequena, esta pode demandar, fazendo-se comparecer a partir do efeito de suas manifestações para os agentes de seus cuidados. Mesmo que a resposta apareça como mutismo, há que se supor que esse sujeito, de alguma maneira, foi marcado pela presença do Outro e articulou alguma concatenação para falar e silenciar. Pode-se, portanto, apontar aí a implantação de um primeiro significante no organismo, em que "o sujeito recebe a sua primeira assinatura, signum, e sua relação com o Outro" (Lacan, lição 12 nov. 1958, inédito). Como lembra Lacan, apenas um olhar dirigido ao organismo é suficiente para constituir um suporte:

Esse olhar do Outro, devemos concebê-lo como interiorizado como um signo. Isso basta. Ein einziger Zug. Não há necessidade de todo um campo de organização e de uma introjeção maciça. Este ponto, grande I, do traço único, este signo de assentimento do Outro, da escolha de amor sobre a qual o sujeito pode operar, está ali em algum lugar no jogo do espelho. Basta que o sujeito vá coincidir ali em sua relação com o Outro para que este pequeno signo, einziger $Z u g$, esteja à sua disposição. Pode-se distinguir radicalmente o ideal do eu do eu ideal. O primeiro é uma introjeção simbólica, ao passo que o segundo é fonte de uma projeção imaginária. A satisfação narcísica que se desenvolve na relação com o eu ideal depende da possibilidade de referência a este termo simbólico primordial que pode ser monoformal, monossemântico, ein enziger Zug. (Lacan, 1991[1960-61], pp.344).

O sujeito é o efeito do apagamento de traços, ou seja, de estranhezas vindas do Outro, pois transforma essas figuras em olhar, gesto, voz... Será a saída da criança da condição de indiferenciação com o emblemático traçado da alteridade, que permitirá sua entrada no campo simbólico. É o Outro que corrobora e reconhece as manifestaçóes despontadas em respostas pelo infans, ao que esse Outro causou. Esse é o deslocamento que o neonato precisa fazer com a incidência do Outro para circular na linguagem: manufaturando "leituras" do que passou, o infans trabalha concatenando os traços e, desse modo, passa a usufruir das possibilidades próprias que o simbólico pode oferecer. Nesse caso, o infans demonstraria um deslocamento ativo que o faria sair da pura relação projetiva para circular na via simbólica. 
A importância em responder às interpelações da criança de uma maneira a lhe conferir sentido e acolhimento, como em um gesto dirigido é que, pelo fato de ser permeado de significação, tal gesto pode permitir o encadeamento das palavras, possibilitando à linguagem circular, fazendo ligação do real do organismo ao campo simbólico. Na tentativa de situar a criança num campo simbólico, muitas vezes, o que a clínica propóe é interpretar os movimentos de criança, deixando soar, de novo, o que ela pode querer dizer, retornando esse gesto de escuta em ato de fala. Considerando as manifestações da criança como pertencentes ao registro da "interpelação", o psicanalista transpõe o real para o registro da imaginarização, na direção de produzir a sua simbolização.

Essa operação clínica considera que é a demarcação de outros traços significantes em atos diversos que permitirá ao sujeito encontrar-se em algum lugar entre os significantes, mesmo que trate de uma posição congelada, tal como ela comparece na psicopatologia do autismo. Afinal, o significante pode, nesse caso, ter permanecido limitado, sem fazer operar o funcionamento significante. Restrito a uma marca sem concatenação a outros significantes, esse primeiro significante teria reduzido o sujeito a petrificar-se nesse lugar pelo mesmo movimento em que poderia tê-lo chamado a funcionar como sujeito: "Ele não pode substituir ali como tal, pois ali só há um, o primeiro" (Lacan, 1988[1964]a). Essa posição que, no autismo, parece restringir seu funcionamento simbólico por manter esse significante paralisado no real pode, porém, ser problematizada com a premissa lacaniana de que o autista é um sujeito verboso (Lacan, 1998 [1975], p. 12-13). Como teriam sido possíveis outras construçôes significantes a partir da relação com esse primeiro traço demarcado?

\section{O traço unário}

O traço unário nomeia por seu nome próprio. A sua função é fazer aparecer a gênese da diferença numa operação que promova a repetição destacada, não do símbolo, mas da entrada no real como significante em uma diferença absoluta. A função do nome próprio pelo significante amarra algo em que o sujeito se constitui. Por isso, o significante representa para outro significante o sujeito. $\mathrm{O}$ sujeito barrado é isso que representa para um significante um sentido, desse significante de onde ele surgiu.

A função do traço unário reside em assegurar a repetição pela sua função de fundação. Com a instauração do traço unário, o sujeito quer repetir a experiência de satisfação que obteve na resposta do Outro, na volta que deu 
e não percebeu. A relação típica do sujeito constituído pelo significante é o único suporte possível daquilo que é, para nós, a experiência de satisfação. O automatismo da repetição faz insistir alguma coisa que é do significante, pois foi ele que marcou um instante de satisfação.

A distinção da palavra do nível pré-verbal, signo, à linguagem está justamente no fato da emergência da função do significante. $O$ traço unário é o instrumento da identificação do sujeito que tem plena relação com a estrutura do simbólico. Ele é "o rosto sem véu do Einziger Zug da identificação", aponta Lacan, em referência ao termo usado por Freud para qualificar um tipo de identificação (Lacan, 1961-1962a, inédito). $\mathrm{Na}$ identificação, há certo abandono ou perda do objeto no qual o eu se identifica, copiando o objeto amado ou o não amado.

A repetição no inconsciente é a procura da unicidade significante original para sempre perdida. Isso se joga antes mesmo que o sujeito se dê conta. Ele repete sem saber, saindo de sua imanência vital. Há a privação real de um objeto simbólico. Essa privação não acontece pelo interdito, mas pelo não dito. Há primeiro o nada, o vazio $(-1)$ em que o sujeito não é subjetividade. Na volta não contada entre desejo e demanda do Outro é que se marca a privação do sujeito, privação na coisa. Assim, o sujeito se engana, crendo que existe um objeto pleno que trará satisfação plena e, mais ainda, que ele se encontra no Outro.

O traço unário é, portanto, inscrição de um significante que marca a diferença fundamental, retirando o ser de sua condição de pura necessidade, inserindo-o no campo do Outro, da linguagem. Ao se referenciar a um ponto de diferença que se exclui, o ser posiciona-se num conjunto fechado em relação ao enxame de significantes. Será a resposta do agente materno a um movimento da criança, S2 como resposta ao S1, que este $S 1$ poderá ser marcado. Portanto, o choro só ganhará estatuto de apelo (S1) quando houver a resposta do agente materno (S2) que confira uma satisfação, de modo a marcar uma pulsação na descontinuidade que diz o que o choro pode significar (do apelo a uma demanda). É, então, por meio do ato que intervém, que haverá a promoção da satisfação e o franqueamento de uma posição.

A emissão do grito marca aquilo que não se sabe, foi perdido, mas é sentido como buraco que rompeu com a alternância do mítico gozo pleno. O grito é elevado à função significante e surge como demanda de uma urgência indizível. É no traço unário que o sujeito irá se identificar ao gozo na repetição. Há agora um empuxo de retorno ao gozo pleno. $\mathrm{O}$ 
sujeito surge do estabelecimento do $S 1$, surgido no traço unário que traz consigo arrastado o S2, representando a perda do objeto e a marca da instalação da função significante, que é amarrado pelo simbólico sobre o real, mas é efetuado pela relação imaginária mãe-filho. O princípio do prazer começa a funcionar a partir dessa perda do gozo pleno, marcando picos de necessidade e de satisfação, operando ora a favor da vida, ora a favor do inanimado. Mas, para poder obter o gozo perdido, o sujeito passa a agir em busca do reencontro com o objeto, por isso caminha na repetição a fim de conseguir obter aquela suposta satisfação primeira de gozo. O sujeito está agora submetido à linguagem, e precisa do saber do Outro para obter os caminhos do gozo.

Para Lacan (1961-1962b), o traço, além de ser distinto de um signo, pode ser localizado como letra, essência do significante. Ao se equivaler à letra, o traço denota o nível mais arcaico e redutível, simples e elementar. Lacan anuncia que a letra pode ser transmitida, pois é efeito do discurso e, por isso, pode-se fazer rasura, desaparecimento, mas ela comporta uma face não significante do significante e tem a ver com o gozo, com o real, o que permite, no entanto, que gozo e escrita se amarrem. Essa letra inscrita marca o sujeito que, mesmo fazendo outras escritas sobre essa primeira, ficará marcado com esta para sempre.

Soler (2005) esclarece que o filho inicialmente se oferece aos engodos da sedução para realizar o que os ditos e condutas da mãe deixam entrever do objeto de seu desejo. Nesse processo, Lacan (1998[1960]) elucida, ainda mais, que a mãe é elevada à potência simbólica, detentora dos poderes da fala, de tal forma que o seu "dito primeiro decreta, sentencia, legifera, é oráculo, confere ao outro real sua obscura autoridade” (p. 822), deixando no infans uma cicatriz indelével.

O Outro deixa uma marca na memória, na qual reencontramos a voz, às vezes devastadora e persecutória de suas palavras, seus imperativos e seus comentários inesquecíveis. É a isso, talvez, que Lacan (1998 [1985], p. 10) se referisse ao teorizar sobre alingua enquanto algo falado por alguém e escutado por outro que, na sua particularidade, revelará tal marca, posteriormente, nos sonhos, num tropeço ou em qualquer outro tipo de fenômeno linguageiro. E a criança, destarte, ao começar a esboçar suas primeiras palavras, antes de qualquer frase, provará que há algo nela, uma peneira que se atravessa, por onde a água da linguagem chega a deixar algo na passagem, alguns detritos com os quais ela vai brincar, com os quais, necessariamente, ela terá que lidar. É isso que lhe deixa toda essa atividade não refletida, restos aos quais, mais tarde, porque ela 
é prematura, agregar-se-ão os problemas do que a assustará. Graças a isso, ela vai fazer a coalescência, por assim dizer, dessa realidade sexual e da linguagem (Lacan, 1998[1985], p. 11).

Nesse ponto arcaico, no qual um significante é cunhado, supõe-se a origem do inconsciente. Quando o sujeito fala, recorre aos enunciados que estão em referência à enunciação de algo que ele não sabe, sendo, na verdade, em princípio, o nada. O inconsciente é esse lugar onde há a fala pelos efeitos de retroação dos significantes; o sujeito é isso que se nomeia da leitura que faz do traço unário naquilo que designa a diferença absoluta. O sujeito não saberá nunca qual foi o objeto mítico de sua satisfação. O que ele terá à mão será apenas o novelo, aquele do neto de Freud no fort da (em Além do princípio do prazer, texto de 1920), ou como Lacan associa, ao objeto transicional (cunhado por Winnicott).

Entretanto, a consideração desse nada a partir da separação do campo narcísico, de um outro campo, desta vez, campo pulsional, permite a Lacan articular o objeto pulsional, objeto $a$, como o objeto perdido causa do desejo que se imiscui, mas que se diferencia dos objetos de amor do campo narcísico, localizáveis na mãe e em seus instrumentos objetais. A relação que o inconsciente efetua na repetição com o que é percebido tem relação com o que falta e sempre faltará e, nessa falta marcada, o objeto é perdido (o objeto $a$ ).

\section{O objeto olhar}

O olhar se especifica, para Lacan (1988[1964]b, p. 83), como o mais inassimilável e inapreensível entre os objetos. É pelo fato de ele ser desconhecido que ele se torna simbolizável na ilusão do "ver-se vendo$s e$ ". Há ambiguidade no registro da pulsão escópica, porque o sujeito não sabe qual vetor surgiu primeiro: dele ou do Outro? Com base na perspectiva de haver um nada antes de haver sujeito, um olhar o constitui como condição de existência: "No que estou sob o olhar, sou olhado e se olho, aquele olhar desaparece" (Ibidem). Esse olhar que o ser encontra é o olhar não visto, mas é um olhar da dimensão do imaginado, vindo do campo do desejo do Outro. É uma maneira de reconhecer o objeto $a$ em um objeto representável da pulsão.

No nível escópico, há o desejo do Outro, e o olhar pode funcionar como objeto $a$, porque evidencia um quiasma, ou mesmo um desencontro, no qual o sujeito se apresenta como o que não é, e o que se mostra não é o que ele quer ver. Apesar de haver mancha no olhar, engano no olho 
(“trompe-l'oeil') quando este olha, o órgão, a partir do momento que serve à função do olhar, registra algo a partir de um ponto.

Em A Lógica da fantasia (1966-1967a, lição 16 nov. 1966, inédito), Lacan esclarece que o pequeno $a$ resulta de "uma operação de estrutura lógica efetuada não in vivo, nem sobre o vivente, nem é necessariamente a 'libra da carne'". Mas pode ser representado no corpo, por meio de uma operação de estrutura lógica sob formas de peças destacáveis, no seio, no cíbalo, no olhar, na voz, e por isso se localizam fundamentalmente ligados ao corpo. Eis do que se trata no objeto $a$.

Nesse processo, o infans dependerá do imaginário da mãe em sua estruturação subjetiva. Lacan, diante disso, coloca uma questão: "Em que essa relação se articula em termos lógicos da dependência da função do significante?", ao que ele responde, com a ajuda de Pontalis, que

A menor falta (ou, falha) concernente à pertinência de cada um dos termos dessas três funções, o sujeito, o objeto (objeto de amor) e do além deste, o objeto a, é que ela poderia ser obscurecida pela imaginação do sujeito no que diz respeito à relação que se tratava de se esboçar.

Talvez seja aí que o sujeito em constituição, em relação ao objeto $a$ e ao Outro, pode se colar a uma representação oferecida pelo outro à sua condição de não senso, de ser-em-falta? Será que ele pode se locar somente sob o viés imaginário, sem o limite do simbólico que oferece o viés do equívoco? A ecolalia e o automatismo não representariam um congelamento no laço dos registros do real ao imaginário?

Lacan (1966-1967b) explica que o sujeito começa com o corte. Um corte cujas paredes vêm no traço, não menos imaginário, se cruzar. No entanto, o corte ultrapassará a linha imaginária, instaurará uma mudança total da estrutura da superfície, de forma que essa estrutura inteira se torne o objeto a. Desse modo, ele se torna um disco achatável, com um direito e um avesso, do qual não se pode passar de um ao outro sem ultrapassar uma borda. $\mathrm{O}$ infans, então, passaria por esse primeiro corte, ele mesmo como objeto a materno. Esse objeto a guarda aí uma relação fundamental com o Outro, e o sujeito ainda não apareceu absolutamente com o único corte que, ao instaurar o significante no real, deixa cair primeiro esse objeto estrangeiro que é o objeto a. Lacan fala que é a mesma coisa fazer um só corte ou fazer dois, mas, se tal corte é feito no tecido onde se trata de exercer esse corte, em um duplo corte, desprende e destitui o que foi perdido no primeiro corte, a saber, uma superfície cujo direito continua 
como avesso. É aí que Lacan transpõe a noção idealista do dentro e do fora. Há a restituição, a não separação primitiva da realidade e do desejo, quer dizer, a realidade humana não é nada mais que a montagem do simbólico e do imaginário nesses enlaces e que o desejo, no centro da realidade, é também o que corre no entrevisto, entrevisto quando a máscara, que é a do fantasma, vacila. Lacan se remete a Spinoza para dizer que tal fato é a mesma coisa da fórmula do filósofo, de que "o desejo é a essência do homem", salvo que, na psicanálise, "o desejo é a essência da realidade". Sobre o significante, o que não está ali, ele não o designa, antes ele o engendra. O que não está ali, na origem, é o próprio sujeito, só o objeto. Só há sujeito por um significante e para o outro significante. O Uverdrangung, recalcamento originário, é isso: o que um significante representa para outro significante (S1-\$-S2).

O olhar, portanto, está na série dos objetos pulsionais entre os outros objetos, oral, anal e invocante, porque a direção do olhar só faz contorno ao que acredita ver e, nesse movimento pulsional de dirigir um olhar, há a satisfação e a possibilidade de representar o que falta. Quando o sujeito lança seu olhar não tem garantia de estar vendo com certeza aquilo que, em si, é; pode apenas ter a ilusão do que acredita ter olhado (como nos casos do mimetismo, por exemplo, ou nos quadros de muitos pintores), a realidade pode se confundir para quem olha. Na dialética do olho e do olhar, Lacan (1988 [1964]c, p. 100) afirma que não existe coincidência entre eles, mas, na verdade logro, insatisfação. Na pressa de concluir o objeto olhado do qual o sujeito dependia, o objeto $a$ cai na falha entre o que se supôs ter visto e o que o sujeito afirma, de modo que ele se desprende dessa suposição (Porge, 1994). A mancha sempre oculta o que há por detrás dela, preparando para a possibilidade do ressurgimento do campo do desejo (Lacan, 2005 [1962-63]a, p. 303), porque a revelação pode conferir satisfação, mas sempre com um aquém, nunca totalmente satisfeito.

A pulsão escópica funciona, assim, como constituinte. Ela convoca o ser, pelo desejo ao Outro, a comparecer e a existir por meio do dar-aver. No registro escópico (Lacan, 1988[1964]d, p. 114), o sujeito não é indeterminado, mas é determinado pelo corte do objeto a na fascinação. No tempo do olhar, o que acontece é uma dialética da precipitação identificatória no instante de ver. $\mathrm{O}$ olhar, além de não só terminar o movimento, o faz cristalizar, porque no momento de ver há um efeito fascinatório (fascinum) sobre quem está dirigindo o olhar. Esse instante de ver faz uma sutura do imaginário ao simbólico, efetuando 
uma precipitação do tempo do olhar, quando no gesto há uma parada e, assim, o fascínio da invídia. Lacan fala que "há um apetite do olho naquele que olha" (Ibidem, p. 112), e o fato de o olho estar desesperado por um olhar é que torna preciso dar o alimento pacificador num gesto de olhar. Assim, a raiz da pulsão escópica consiste no fato de que o sujeito se vê a si mesmo por meio do olhar do Outro desejante.

A importância de diferenciar e tentar marcar um lugar para a criança, permitindo o seu surgimento singular na intervenção despendida por meio do olhar atento, pode gerar uma expectativa no sujeito em porvir, conforme, entre o "ir e o vir", esse ser fica esperando o retorno daquilo que passou. Nessa expectativa, já há, nesse ponto, uma antecipação sobre o "ir". O que acontece, então, é a possibilidade de haver delimitação de um saber duplamente suposto: do Outro e do ser na vertente escópica. Mas a verificação dessa suposição só se constata num segundo tempo.

A transferência, no emprego pelo psicanalista de um saber suposto, ao não duvidar da presença de um sujeito vivo, faz antecipar um sujeito antes que ele mesmo se localize. A suposição de saber sobre a criança, quer dizer, sujeito em porvir passível de uma "leitura", é o que pode permitir a entrada da criança na demanda. Ao haver oferta de um olhar dirigido, é possível que a criança retorne esse movimento pulsional numa resposta, com outro olhar (ou outro movimento), e no encontro de olhares, faz-se o desdobrar do movimento pulsional para outros objetos.

\section{O objeto voz, ainda}

A voz também funciona como constituinte num gesto dirigido à criança por uma alteridade. Lacan (2005[1962-63]b, p. 299-300) explica que a voz tem como modelo o pote, porque o pote, por ser um tubo, exemplifica como se ressoa e circunscreve o vazio. Ao representar por meio de emissóes de sons o nosso vazio, a voz surge do aparelho acústico, fonológico, mas só como um ressoar desse aparelho. A voz responde ao que é dito, mas não pode responder por isso. Para responder, ela precisa ser incorporada como alteridade do que é dito. Esse processo de incorporação (identificação dada ao corpo do que vem do Outro) e o retorno num ressoar demonstram um movimento que pode ser conferido nos monólogos infantis. Ou seja, o que isso demonstra, para Lacan, nada mais é que a presença reveladora "das tensões denominadas de primordiais no inconsciente, é análogo, em todos os aspectos, à função do sonho. Tudo se passa na Outra cena” (Ibidem, p. 298). Por isso, faz-se 
crítica à denominação desse monólogo como egocêntrica.

A linguagem é veiculada ao sujeito de muitas maneiras, não só pela voz, mas parece que há uma relação com a sonoridade no processo de constituição dessa "concha acústica" em que nos formamos. A voz ressoa no vazio, não como modulada e sonora, numa música, mas como um imperativo que reclama obediência ou convicção, situando-se em relação à fala articulada (Ibidem, p. 300). O sujeito pode não reconhecer sua voz quando canta, por exemplo, denotando o lugar do Outro no vazio, no que ele tem em sua dimensão de não conferir garantias. É por isso que a voz não é assimilada e, sim, incorporada, identificada.

Para Lacan (Ibidem, p. 322), todos os fatos anatômicos (funcionamento do órgão fálico, do aparelho fonológico com a voz, a antecipação da imagem especular) conjugam-se com o objeto $a$, porque eles vêm bloquear um lugar, a partir da constituição subjetiva que resulta na dominação do sujeito que fala sobre o sujeito que compreende, o sujeito do insight. A progressão e regressão do movimento pulsional em volta dos objetos (oral, anal, escópico, invocante) denotam os caminhos pelos quais o sujeito passa no processo de sua constituição. Não é uma circularidade de fases, mas uma aderência dos objetos ao objeto $a$, como uma "pseudossubstituiçãa" de um encontro com o verdadeiro objeto de satisfação, o que não passa de um engodo, mas que encontra no sujeito um valor de destino.

\section{Em vias de conclusão}

É o Outro, portanto, que permite a entrada do ser na vida, com a marcação fundamental de um significante na posição de letra. Com a instalação do traço unário na marcação da falta na descontinuidade, há a inserção do sujeito na cadeia significante, que barra o ser de necessidade, produzindo a pulsão. A pulsão é o resultado dessa operação significante sobre a necessidade. O sujeito não pode deter a pulsão, nem evitando nem escolhendo e, dessa forma, ele fica dividido e marcado pelo significante e pela pulsão (Soler, 1997). Algo não sabido, que não se escreve nem se inscreve, circula num movimento de curto-circuito, num vaivém, como maneira encontrada pelo sujeito para satisfazer a pulsão.

A pulsão é o efeito que a cultura faz sobre o ser instintual. A in tromissão cultural perverte o puro ser pelo laço social que cria as trocas humanas, não mais regidas pela natureza. Entretanto elas só operam efetivamente quando atam o corpo narcísico à montagem da pulsão, pela 
qual a sexualidade participa da vida psíquica na mesma conformidade da estrutura de hiância do inconsciente. A pulsão é consequência da articulação que só a criança faz, na linguagem, com a demanda do Outro. A criança se aliena ao Outro, buscando a satisfação, mas, ao considerar a demanda deste, que nunca lhe corresponde inteiramente, dele se distancia, separando-se. Essa não reciprocidade exige a atividade do sujeito, ou seja, a pulsão. Só se separando pode distinguir-se do Outro, para ir, com sua libido, ali buscar o que falta, demarcando o desejo. A libido representa essa separação da sexualidade biológica humana na organização trazida pelo significante. Ela é o órgão irreal da pulsão que se articula ao real, escapando ao corpo narcísico (feito pelo Outro) para estender-se para além, indo buscar algo fora. Dessa perspectiva, a pulsão é algo estritamente humano, de pura atividade e movimento em se fazer feiçoar, que parte da borda de uma zona erógena para ir buscar algo que responderia no Outro à sua satisfação (Lacan, 1988 [1964]e, p. 184;195).

Nos casos de crianças que esboçam um funcionamento sob o espectro autista, psicótico, débil, ou ainda, em casos de depressóes ditas anaclíticas, faz-se urgente a apresentação de um Outro simbólico que efetivamente marque um traço distinto ao que já tenha sido marcado, permitindo desdobramentos significantes não somente por atos de fala, mas também por meio de outros recursos simbólicos que façam ligação entre o simbólico e o imaginário. Como mostraram os Lefort (1984[1951-52]), a massa corpórea do Outro (no psicanalista), ainda que seja um obstáculo real, pode ser também um material de uso, palco oferecido para a figurabilidade lúdica que, nas mãos das crianças, pode ficar marcado por essas intrusões. Por meio da passagem pelo imaginário, o psicanalista trabalha com o campo simbólico: ao incluir na trama a humanidade da linguagem, muitas vezes retira do limbo do real um sujeito. Paradoxalmente, é ao ser malsucedido nessa empreitada de tentar significar a criança, ou seja, ao fracassar na procura de reciprocidade entre as manifestações da criança e a interpretação destas, que o enlaçamento da pulsão pela criança pode aí ocorrer. Afinal, o que diz respeito à atividade do próprio sujeito, ou seja, imiscuir-se por meio da atividade da pulsão nesse circuito da fala que visa imaginariamente a operar reciprocidades na equivocidade da linguagem é escolha insondável, que escapa a alçada do clínico e só se sustenta como uma aposta. 


\section{Referências}

Lacan, J. (1985). Conferência em Genebra sobre o sintoma. Revista Opção Lacaniana, 23, dezembro de 1998, p. 6-16.

Lacan, J. (1958-1959). O seminário: livro 6: o desejo e sua interpretação. Inédito.

Lacan, J. (1991). O seminário: livro 8: a transferência. (Dulce Duque Estrada, trad.; Romildo Rego Barros, rev.). Rio de Janeiro: Jorge Zahar. (Trabalho original publicado em 1960-1961).

Lacan, J. (1961-1962). O seminário: livro 9: a identificação. Inédito.

Lacan, J. (2005). O seminário: livro 10: a angústia. (Vera Ribeiro, trad.). Rio de Janeiro: Jorge Zahar. (Trabalho original publicado em 1962-1963).

Lacan, J. (1988). O seminário: livro 11: os quatro conceitos fundamentais em psicanálise. (M. D. Magno, trad.). Rio de Janeiro, Jorge Zahar, 1964.

Lacan, J. (1966-1967). O seminário: livro 14: a lógica do fantasma. Inédito.

Lacan, J. (1998). Subversão do sujeito e dialética do desejo no inconsciente freudiano. In: Escritos. (Vera Ribeiro, trad.). Rio de Janeiro: Jorge Zahar. (Trabalho original publicado em 1960)

Lefort, R. \& R. (1984). O caso Nádia ou o espelho. In: O nascimento do Outro. Salvador: Biblioteca Freudiana Brasileira. (Texto original publicado em 1951-1952).

Neves, B. R. C. (2010). De um olhar ao Outro: a intervenção da psicanalista Rosine Lefort com a criança Nádia. Dissertação de Mestrado, Programa de Pós-graduação em Psicologia, UFMG, Belo Horizonte.

Porge, E. (1994). Psicanálise e tempo: o tempo lógico de Lacan. Rio de Janeiro: Campo Matêmico.

Soler, C. (1997). O sujeito e o Outro I. In: Feldstein, R., Fink, B., Jaanus, M. Para ler o seminário 11 de Lacan. (Dulce Duque Estrada, trad.). Rio de Janeiro: Jorge Zahar. 